\title{
Can Silver nanoparticles be an answer to combat the drug resistance?
}

\author{
Anila A. Mathews ${ }^{1, *}$, Bijoy Krishnan $\mathrm{K}^{2}$ \\ ${ }^{1}$ Professor, ${ }^{2}$ Microbiologist, ${ }^{1}$ Dept. of Microbiology, ${ }^{1}$ Government Medical College, Palakkad, ${ }^{2}$ School of Health Sciences, \\ Calicut University, Malappuram, Kerala, India
}

*Corresponding Author:

Email: mathewsanila3@gmail.com

\begin{abstract}
Introduction: Wide spread usage and irrational use of antibiotics results in resistance and it is a major problem worldwide. Hence there is a need for alternatives.

Objective of our Study: This study was conducted to evaluate the antimicrobial property of Silver nanoparticles, synthesized using neem leaf extract.

Material and Methods: The microorganisms used for the study were Staphylococcus aureus (Methicillin sensitive and Methicillin resistant), E. coli (ESBLs, Non ESBL, carbapenemase producers) and Candida species. These organisms were isolated from different infections like skin and soft tissue infections, urinary tract infections and the antimicrobial property of Silver nanoparticle to these microorganisms were tested.

Results: Silver nanoparticles, synthesized using neem, showed good antimicrobial activity against these organisms compared to the other plant extracts like neem leaf extract studied.
\end{abstract}

Conclusion: Hence Silver in the form of nanoparticle can be a better alternative for treatment of different infections.

Keywords: Antimicrobial Resistance, E. coli, Candida Species, MRSA, Silver Nanoparticles.

\section{Introduction}

Antimicrobial resistance is a major problem both in the hospitals and in the community and this increasing antibiotic resistance result in long term hospital stay, failure to respond to therapies and in turn becomes a financial burden. ${ }^{1,2}$ A 2011 national survey of infectious disease specialist conducted by the IDSA Emerging Infections Network found that more than $60 \%$ of participants had come across a pan resistant untreatable bacterial infection within previous year. Nearly two million Americans developed hospital acquired infections every year and thus resulting in 99000 deaths mostly due to antibacterial resistant pathogens. ${ }^{1}$

Each year approximately 600 deaths are occurring from infections caused by carapenem resistant Klebsiella species and E. coli. ${ }^{2}$ Extended spectrum betalactamse producers (ESBL) producing enterobacteriaceae causes nearly 2600 hospital acquired infections and 11700 deaths per year. ${ }^{2}$ There are reports that duration of hospital stays for patient with antibiotic resistant infections prolonged by 6.4 to 12.7 days collectively adding an extra eight million hospital days. ${ }^{1}$

Widespread use of antibiotics promotes the spread of antibiotic resistance. ${ }^{1,3}$ With increase in the rates of ESBLs, carbapenemase producers and Methicillin resistant Staphylococcus aureus (MRSA) in the hospitals and community, ${ }^{3}$ there is a need for alternatives. Silver, which has been used from time immemorial as Silver nitrate, Silver sulfadiazine can be used for treatment of burns and Silver foils applied to surgical wounds was said to improve healing and reduced post-operative infections. ${ }^{4}$ Nanotechnology is now the science of today and metallic Silver in the form of nanoparticles can be used as a potential antimicrobial agent. ${ }^{5,6}$

The antimicrobial activity of Silver has been well known since ancient times and it has been demonstrated, that in low concentrations, Silver is non toxic to human cells. ${ }^{7}$ Azadirachta indica (neem) is also reported to have antimicrobial effect against different microorganisms like Staphylococcus aureus, Pseudomonas aeruginosa, Proteus mirabilis and Enterococcus fecalis. ${ }^{8}$

This study was undertaken to see the antimicrobial effects of certain plant extracts like neem and Silver nanoparticles synthesized using neem on different bacteria including antibiotic resistant strains of Staphylococcus aureus (MRSA) E. coli (ESBL) and E. coli carbapenemase producers and Candida species.

\section{Material and Methods}

The study was conducted at a tertiary care hospital in South India, after obtaining the Institutional Ethical clearance. A total of 120 bacterial isolates and fifty candida species, isolated from different infections, were used for the study.

\section{Preparation of Leaf Extracts}

Preparation of Neem Leaf Extract: Fresh leaves of neem were washed thoroughly with distilled water and air dried. These leaves were ground to get the fine powder. $30 \mathrm{gm}$ of dried powder was boiled in $100 \mathrm{ml}$ of phosphate buffer, pH 8.0 for 30 minutes. After cooling at room temperature, it was centrifuged at $6000 \mathrm{rpm}$ for 10 minutes and filtered. The filtrate was stored at $4^{\circ} \mathrm{C}$ for further experiments and was used as reducing and stabilizing agent for $1 \mathrm{mM}$ of $\mathrm{AgNO}_{3}\left(\mathrm{AgNO}_{3}, 99.99 \%\right.$, Sigma-Aldrich). 
Synthesis of Silver Nanoparticles: The extract of neem leaves $(18 \mathrm{ml})$ was mixed with $50 \mathrm{ml}$ of $1 \mathrm{mM}$ Silver nitrate $\left(\mathrm{AgNO}_{3}\right)$ solution in 1:2.78 ratio in a conical flask under aseptic condition. The flask was kept in shaking water bath at $37^{\circ} \mathrm{C}$ in dark for 5 hours. A change in the color was observed indicating the formation of Silver nanoparticles. The quality of the Silver nanoparticle prepared was checked before testing its antimicrobial effect. ${ }^{4}$ (Fig. 1) The antimicrobial effect of the Silver nanoparticle, synthesized using neem, was studied.

Preparation of McFarland Standard: About 0.5 McFarland equivalent turbidity standard was prepared by adding $0.6 \mathrm{~mL}$ of $1 \%$ barium chloride dehydrate solution $\left(\mathrm{B}_{\mathrm{a}} \mathrm{Cl}_{\mathrm{z}} 2 \mathrm{H}_{2} \mathrm{O}\right)$ to $99.4 \mathrm{~mL}$ of $1 \%$ sulphuric acid solution $\left(\mathrm{H}_{2} \mathrm{SO}_{4}\right)$. A small volume of the turbid solution was transferred to capped tube of the same type that was used to prepare the test and of control inocula. This was stored in the dark at room temperature.

Thirty Methicillin sensitive Staphylococcus aureus (MSSA) and twenty Methicillin resistant Staphylococcus aureus (MRSA), 60 E. coli, (ESBL and non ESBLs) and $10 \mathrm{E}$. coli (carbapenemase producers) isolated from different infections like skin and soft tissue infections, and urinary tract infections were used for the study. The antimicrobial effects of Silver nanoparticles (Ag-NPs) and neem leaf extracts, were tested against these organisms.

Antibiotic Sensitivity Testing: Kirby Bauer disk diffusion method was used. The microorganisms were grown at $37^{\circ} \mathrm{C}$ for 4 hours and prepared to match turbidity equivalent to McFarland standard No. 0.5 (National Committee of Clinical Laboratory Standards, 2000). Then $100 \mu \mathrm{L}$ of the suspension was spread on the test plate (Muller Hinton agar). Sterile discs $(6 \mathrm{~mm}$ diameter) were impregnated with $50 \mu \mathrm{g} / \mathrm{ml}$ and 100 $\mu \mathrm{g} / \mathrm{ml}$ of Silver nanoparticle prepared and placed on the surface of the test plate. Plates were incubated at $37{ }^{\circ} \mathrm{C}$ for 24 hours and zones of inhibition were calculated by measuring the diameter in $\mathrm{mm}$.

Statistical Analysis: Analysis was done using SPSS version. 18 Fishers exact test was used for statistical analysis. The antimicrobial effects of Silver nanoparticle and neem were compared using Fishers exact test.

\section{Results}

Among the 120 isolates tested, fifty Staphylococcus aureus isolates which were isolated from pus samples of skin and soft tissue infections were subjected to susceptibility testing to different plant products like neem leaf extracts, and Silver nanoparticles. Among the fifty Staphylococcus aureus, 30 were Methicillin sensitive Staphylococcus aureus (MSSA) and twenty were Methicillin resistant Staphylocccus aureus (MRSA). Among the MSSA isolates studied, all were sensitive to Silver nanoparticles (zone diameter ranged from $16 \mathrm{~mm}$ to $29 \mathrm{~mm}$ ) whereas, only 14 were sensitive to neem leaf extracts. It was statistically significant $(\mathrm{P}$ value $<0.001$ ) and the odd ratio was 2.143 .

Among the twenty MRSA isolates, only two were sensitive to neem extracts, but all the twenty were sensitive to Silver nanoparticles with zone diameters of inhibition ranging from $16 \mathrm{~mm}$ to $28 \mathrm{~mm}$. Among the 30 E. coli non ESBL's isolated, 15 were isolated from skin and soft tissue infections, (14 from Pus samples and 1 from tissue) and 15 were from urinary tract infections. Among the $30 \mathrm{E}$. coli isolated and tested, none were sensitive to neem extracts, but they showed promising result to Silver nanoparticles. Among the $30 \mathrm{E}$. coli ESBLs isolated, 24 were isolated from urinary tract infection and 6 were from skin and soft infections. Among these $30 \mathrm{E}$. coli ESBLs, none were sensitive to neem extract, but all these isolates were sensitive to Silver nanoparticles. Silver nanoparticles showed good activity against E. coli carbapenemase producers compared to neem. Among the 50 candida species tested, 29 were isolated from urinary tract infections, 13 were from pneumonia cases, 4 were from vaginitis cases and 4 from skin and soft tissue infections. Of the 50 candida species tested, none were sensitive to neem, but all were sensitive to Silver nanoparticles.

Table 1 shows the antimicrobial activity of Silver nanoparticle AGNP3 and neem to different microorganisms tested with their zone diameters in $\mathrm{mm}$.

Table 1: Antimicrobial susceptibility of silver nanoparticles and neem leaf extract to the different microorganisms tested

\begin{tabular}{|l|c|c|c|c|}
\hline Microorganisms & $\begin{array}{c}\text { No of isolates with } \\
\text { Antimicrobial } \\
\text { activity to AGNP3 }\end{array}$ & $\begin{array}{c}\text { Zone } \\
\text { Diameters } \\
\text { (in mm) }\end{array}$ & $\begin{array}{c}\text { No of isolates with antimicrobial } \\
\text { activity to neem leaf extract }\end{array}$ & $\begin{array}{c}\text { Zone } \\
\text { diameters (in } \\
\text { mm) }\end{array}$ \\
\hline MSSA & 30 & $16-29$ & 14 & $18-26$ \\
\hline MRSA & 20 & $16-28$ & 2 & $18-22$ \\
\hline $\begin{array}{l}\text { E. coli (Non } \\
\text { ESBL) }\end{array}$ & 30 & $13-16$ & 0 (all 30 isolates were resistant) & 6 \\
\hline E. coli ESBL & 30 & $13-15$ & 0 (all 30 isolates were resistant) & 6 \\
\hline $\begin{array}{l}\text { E. coli carbapenem } \\
\text { resistant strains }\end{array}$ & 10 & $11-15$ & 0 (all 10 isolates were resistant $)$ & 6 \\
\hline Candida species & 50 & $15-18$ & 0 (all 50 isolates were resistant $)$ & 6 \\
\hline
\end{tabular}




\section{Discussion}

Drug resistance is the greatest problem faced by hospitals worldwide and there are very less antibiotics left to act against many of these drug resistant pathogens. ${ }^{1-3}$

Once an individual is infected with multi drug resistant bacteria, it is not possible to cure easily and he/she has to spend more time in the hospital and requires multiple treatment of broad-spectrum antibiotics, which are less effective, more toxic and more expensive. ${ }^{10}$ This in turn leads to emergence of pan drug and multidrug resistance.

The Silver nanoparticles show efficient antimicrobial property compared with other salts due to their extremely large surface area, which provides better contact with microorganisms. ${ }^{11}$ Biosynthesis of Silver nanoparticles (AgNPs) with ecofriendly plant extracts containing different phytochemicals that can act as both reducing and capping agents forming stable and shape-controlled AgNPs. ${ }^{12}$ There are different studies on antimicrobial effect of Silver nanoparticle on different multidrug resistant microorganism like Staphylococcus aureus, Bacillus subtilis, Salmonella typhimurium, MDR E. coli, Salmonella typhi, Pseudomonas aeruginosa, Klebsiella pneumonia and Candida albicans and they showed some promising results. ${ }^{13-16}$ These results are similar to our studies, which showed that Silver nanoparticle synthesized using neem had antimicrobial effect against Staphylococcus aureus, Candida albicans and MDR E. coli including carbapenemase producing bacteria. This green synthesis method can be used as alternative to chemical method, as it is cheap, pollutant free and ecofriendly. ${ }^{4}$

\section{Conclusion}

Silver nanoparticles, synthesized using neem was found to have good sensitivity to Staphylococcus aureus (MRSA and MSSA), E. coli, ESBL and (carbapenemase producers) and candida species. Therefore these Silver nanoparticle synthesized using neem may act as an ecofriendly antimicrobial agent and can serve as a potent alternative to reduce the burden of multidrug resistance.

\section{Acknowledgements}

We would like to thank PSG College of Pharmacy and Department of Microbiology PSG Institute of Medical Sciences and Research, Coimbatore, India for all the help rendered during the study.

\section{References}

1. Golkar Z, Bagazra O, Pace DG. Bacteriophage therapy: a potential solution for the antibiotic resistance crisis. $J$ Infect Dev Ctries 2014;8(2):129-136. 13.

2. Centers for Disease Control and Prevention, Office of Infectious Disease Antibiotic resistance threats in the United States. Apr, 2013.
3. World Health Organization. Antimicrobial resistance: global report on surveillance 2014. Geneva: WHO, 2014

4. ABG Lansdown, Silver- its antibacterial properties and mechanism of action. J Wound Care 2002;11(4): 125-30.

5. Rai M, Yadav A, Gade A, Silver nanoparticles as a new generation of antimicrobials. Bio Technol Adv 2009;27(1):76-83.

6. Prabhu S, Paulose E.K, Silver nanoparticles: mechanism of antimicrobial action, synthesis, medical applications and toxicity effects. International Nano Letters 2012;2:32.

7. Wen-Ru Li, Xiao-Bao Xie, Qing-Shan Shi, Hai-Yan Zeng, You-Sheng OU-Yang, Yi-Ben Chen Antibacterial activity and mechanism of Silver nanoparticles on Escherichia coli Appl. Microbial Biotechnol 2010; 85:1115-22.

8. Hala A. Mohammed, Al Fadhil A. Omer. Antibacterial activity of Azadirachta indica (Neem) leaf extract against bacterial pathogens in Sudan. Am J Res Communication, 2015;3(5): 246-51.

9. Rai M.K,Deshmukh S.D, Ingle A.P, Gade A.K. Silver nanoparticles: The powerful nanoweapon against multidrug-resistant bacteria. $J$ Appl Microbial 2012;112:841-52.

10. Webb G.F, D’Agata, E.M, Magal P and Ruan S. A model of 499 antibiotic-resistant bacterial epidemics in hospitals. Proc Natl Acad Sci 2005;102:13343-48.

11. Rai M, Yadav A, Gade A Silver nanoparticles as a new generation of microbials. Biotechnol Adv 2009;27:76-83.

12. Kotakadi V.K, Gaddam S. A, Venkata S.K. D, Sai Gopal V.R New generation of bactericidal Silver nanoparticles against different antibiotic resistant Escherichia coli strains, Applied Nanosci 2015;847-55.

13. Lara H.H, Trevino E. N.G, Turrent L. I and Singh D, Silver nanoparticles are broad-spectrum bactericidal and virucidal compounds. J Nano Biotechnol 2011;9:30

14. Maiti S, Krishnan, D, Barman G, Ghosh S.K. and Laha J.K. Antimicrobial activities of Silver nanoparticles synthesized from Lycopersicon esculentum extract. $J$ Analytical Sci Technol 2014;5:40

15. Sukdeb Pal, Yu Kyung Tak, Joon Myong Song, Does the Antibacterial Activity of Silver Nanoparticles Depend on the Shape of the Nanoparticle? A Study of the GramNegative Bacterium Escherichia coli ${ }^{\circ}$ Appl Environ Microbial 2007;73(6):1712-20.

16. Asmita J. G, Padmanabhan P, Suresh P. K and Jangle N.S, Synthesis of Silver nanoparticles using extract of neem leaf and Triphala and evaluation of their antimicrobial activities. Int $J$ Pharm Bio Sci 2012;3(3):88-100 